\title{
TEAPOT TRAVELLING
}

\author{
Roger LEE *
}

Department of Visual Arts, University of Regina, Canada

\begin{abstract}
Traditionally art historians teach art educators the canons of euro-American art history, such as da Vinci's Mona Lisa and Duchamp's the large glass. However, I have discussed the decorative folk arts, yixing teapots from china, in order to understand their Chinese historic and cultural context. Since retirement and the gift of my 350 teapot collection to the art gallery of greater Victoria. I have travelled the world and still I think about and analyse my teapots on my travels in and around china. This visual presentation on PowerPoint will contemporize my analysis of my yixing teapots to show how those same teapots can also reveal how they can be recontextualized illuminating changes in contemporary Chinese culture in themes of the rising middle class, the revival of new religious thought, the belt and road initiative, agricultural capitalism and a sexual revolution? This methodology will encourage art educators to teach art history traditionally but also encourage them to apply their personal travel and experience and possibly their students as well.

Keywords

Yixing Teapots, Chinese Culture, Fashionable Purse, Tourist Markers, Infanticide.
\end{abstract}

\section{Introduction}

In 1994 I used my 400+ Yixing teapots to analyse their relation to Chinese culture, TEAPOT READINGS. With the advent of digital media and the age of smartphone selfies I have now incorporated some of my travel and personal images into this presentation so as make them relevant to the changing contemporary Chinese culture and my travels.

Chinese art historians and critics traditionally looked at teapots with a formalist analysis and what they considered to be the technical expertise of the artist/craftsman. I used post-modernist methodological analysis including historical roots, class, cultural studies and sexuality for a deeper understanding of the small Yixing teapots, made of so-called purple clay, from the Yixing region, about two hours southwest of Shanghai.

Formal These very small teapots are used for brewing tea that is drunk like fine wine or expresso. The brownish clay body retains the heat. The simple shape and form of these two pots show the unity of foot to body, to handle to lid, and body to spout. The modernist teapot has even the look of a fashionable purse!!

Technical merit. The tree trunk teapot illustrates the ability of the artist to copy in great detailed the reality of a tree trunk while the traceried teapot shows the finesse and delicacy of carving possible, much appreciated by Chinese art critics and connoisseurs.

Historical. Traditional symbol of heaven teapot, Pi, a Chinese bronze bell, and the morphing Ding, a three-legged vessel, can now be seen to become an elegant, modern design or even 
tourist markers.

Chinese culture. China has changed in the past 25 years and Chinese culture while still retaining its past has undergone major economic prosperity and western influence that can be seen in my selfies, travel photos. Marriage and its promise of children reflected in the double happiness and double spouted teapots which is also repeated in recent folk art painting but weddings now are western in style with white bridal dresses and the great feasting banquet. Teapots in the shapes of gourds, nuts, seeds encourage fertility/fecundity and numerous offspring in contrast to the past state policy of one child per family that lead to female infanticide, orphans and a demographic imbalance that recently necessitated a change in the law that now allows two children per family. Food is celebrated in Chinese culture. With the rise of private farms and intense cultivation, food has become an economic driver for the proliferation of monster farms for example the growing of yellow chrysanthemums for tea. That wealth is combined with increased standard of living sees the abundance of food and the blossoming of many many restaurants and my food selfies. A paint brush and ink pot teapot high lights Chinese calligraphy and landscape painting. Those forms have been modernized with abstraction and comic book illustrations while the landscape seems to be lost to the rise of artificial gardens and gigantic constructed trees.

RELIGIONS. Is there a loss of Daoist's belief in the supremacy of nature? Daoism's early development saw the rise of traditional Chinese temple architecture that has influenced Asian societies south to Vietnam and east to Korea. Buddhism which arrived from India can be seen in a lotus teapot which originated from a real lotus plants and to become a stylization in a floor pattern. Buddhist temples have an entry arch/gate, torana, seen in this Kuala Lumpur imitation, that influences the construction of similar gateways throughout China and spread as far as the Chinese diaspora travelled, Hongkong, Havana Cuba, Montreal Canada, as entranceways to Chinatown. They have changed from an entrance to a holy place to a tourist marker.

Buddhist temples have become popular again in China not for only spiritual reasons but the Chinese now pray for business success and wealth first!! The Chinese pagoda is a cultural icon of China and its influence across east and south east Asia that can seemingly morph into an Icelandic church and the Canton tower in Guangzhou.

Confucianism respect for the elderly and a society ethically organized is etched onto a teapot and has its counterpart in a photo of an older teacher in Vietnam and the elder stateman god of China, Mao teapot, or now as selfie with Xi Jinping. Bamboo is also revered by Confucians for it is flexible and strong, as man should be. The many bamboo shaped teapots also reflects the extent of bamboo groves in China and its use in commercially made bamboo objects illustrates 
that it is invasively abundant and easy to grow and a very ecological sound renewable resource. Bamboo teapots can also represent the changing class structure in China. The poorer class, who were the majority in 1994, is shown in the first lesser technical quality coloured teapot to the rising middle class and the wealthy all shown by the rise of technical dexterity and finesse in expensive teapots. Fish and dragon-turtle teapots are symbols of Chinese good luck. The proliferation of dragon and lion dances are all part of the Chinese diaspora celebration of longevity and power in China, Vancouver, Hong Kong, even Cuba and Mesopotamia?!!! Popular culture in the shape of farm houses on stilts can still be seen in South East Asia. However, many different forms of houses have evolved in China leading to unique contemporary architectural forms. Chinese bamboo furniture teapots suggest the lower class also but recent designs suggest comfort over design and artist like Ai Wei Wei use it to comment on the upheaval of culture and class. A boat teapot shows its use for peasants transporting their food stuff and to take Chinese oversea is now supplanted by it use for tourism and the government support of the river to sea transport system which has inland manufactured commercial good shipped to the seaports on the east coast. Bridge across the rivers are still important for the local traffic and picturesque views.

A teapot with coins clearly identifies the massive change in Chinese life. The rising standard of living and the expansion of the middle class has seen the use of real everyday objects as subjects for teapots, a log and axe, a suitcase, even a car and tire. But times have changed with the uncontrolled purchase of automobiles, traffic jams and pollution in the large cities of all over China. Chinese technology has however mitigated pollution with the development of the electric car and the expansion of the highspeed train service that is part of the road and belt project that hopes to connect Chinese commercial interest to one third of globe. International trade was first seen in the silk route that went all the way to Iran as represented in these blue and white Chinese Ming vessels now housed in a Tehran museum.

Unlike the west where the human body is the principle subject of art, the nude, Chinese art has been more conservative. The head or hand teapots, are suffice to indicate the body. From the clothed Han dynasty ceramic sculptures the body is fully clothed while it is now shown semi draped or nude revealing the changing sexual openness and freedom beginning in China. The world famous clothing designer Guo Pei exemplifies a new western moral code and design. The male has not undergone a drastic change.

I end with a shoe teapot because I love shoes, Imelda of Vancouver!! Shoe teapots continue in this exhibition from Hong Kong airport!! Recent teapots tend to be more conservative and formal in shape with fine technique. 
My presentation wants to encourage teachers to use handicrafts and everyday art object from other cultures to reveal the historic context of those culture and how culture has changed over time by showing their images in their own travels. It is hoped that it makes the teacher more involved with the subject and the students interest is elevated by the teachers hands on experience.

Note. Researching and organizing your plethora of digital images can be tiresome!

Two hundred Images are coordinated with the bold face text.
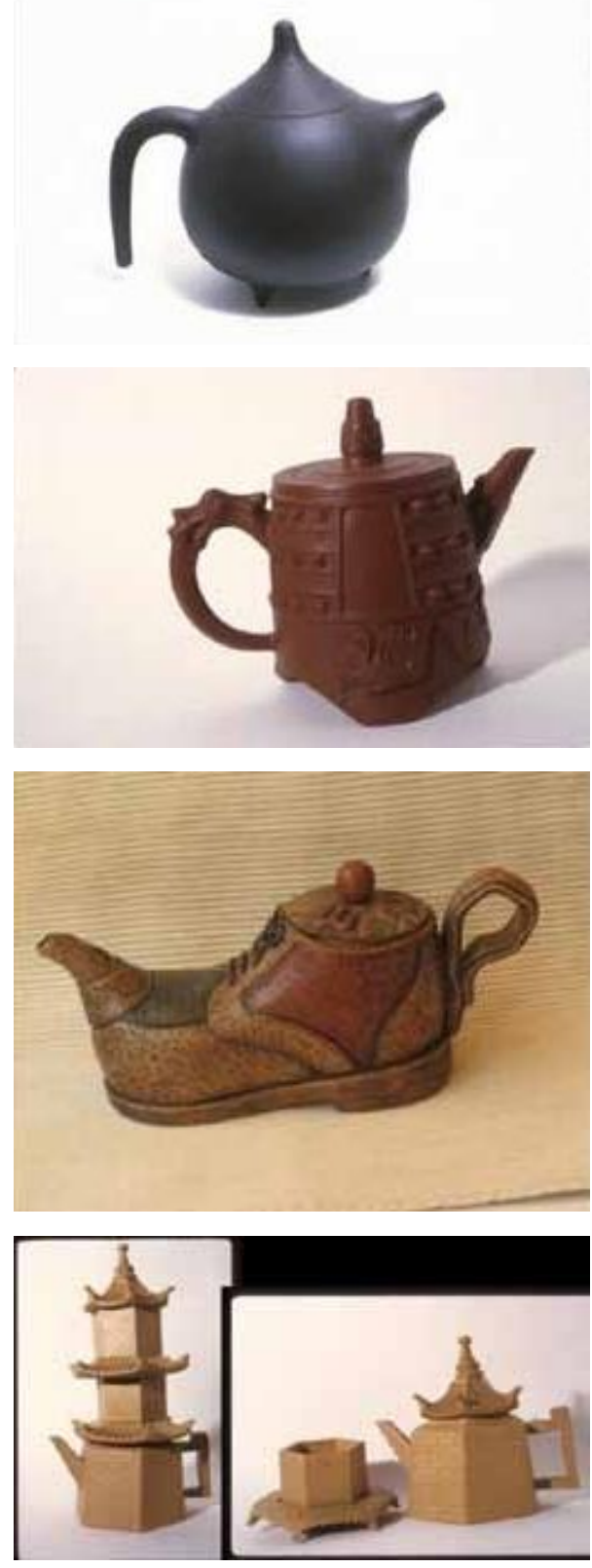

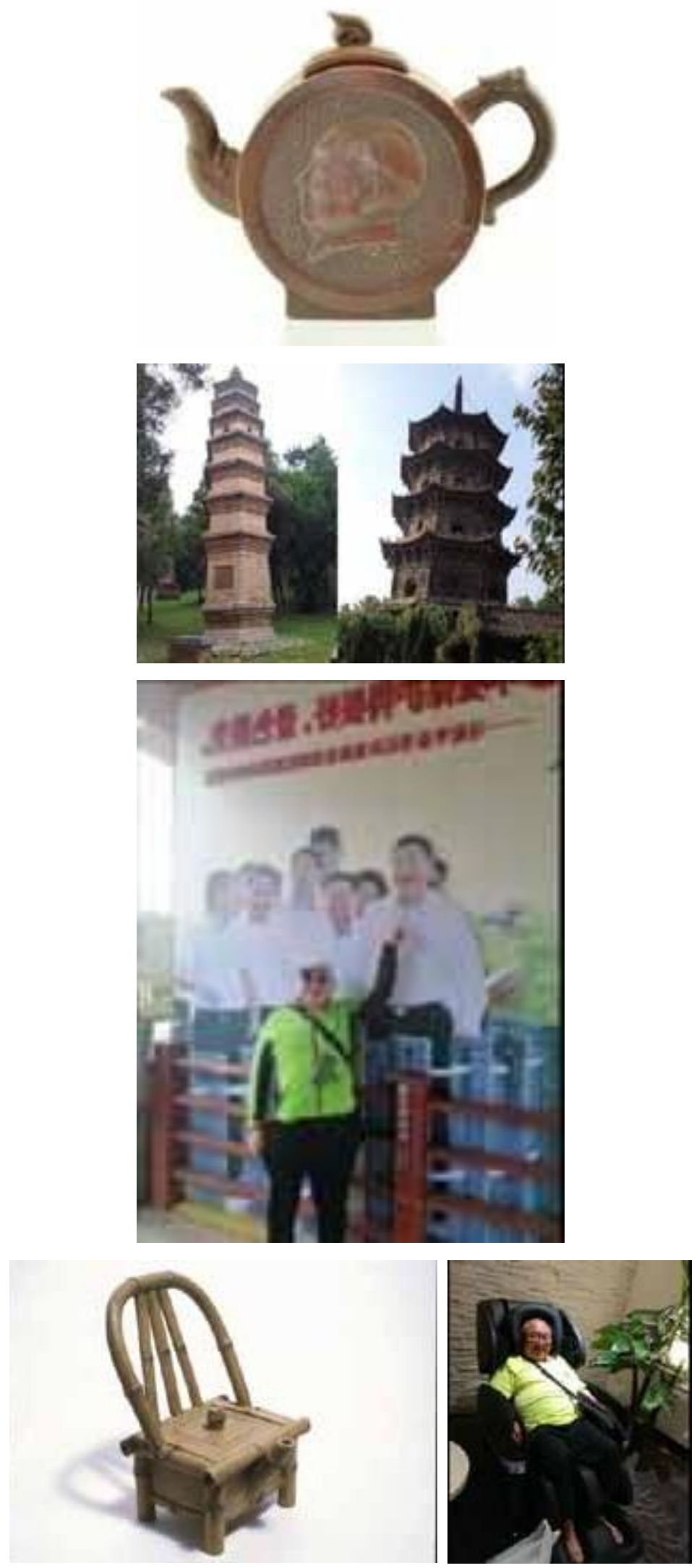

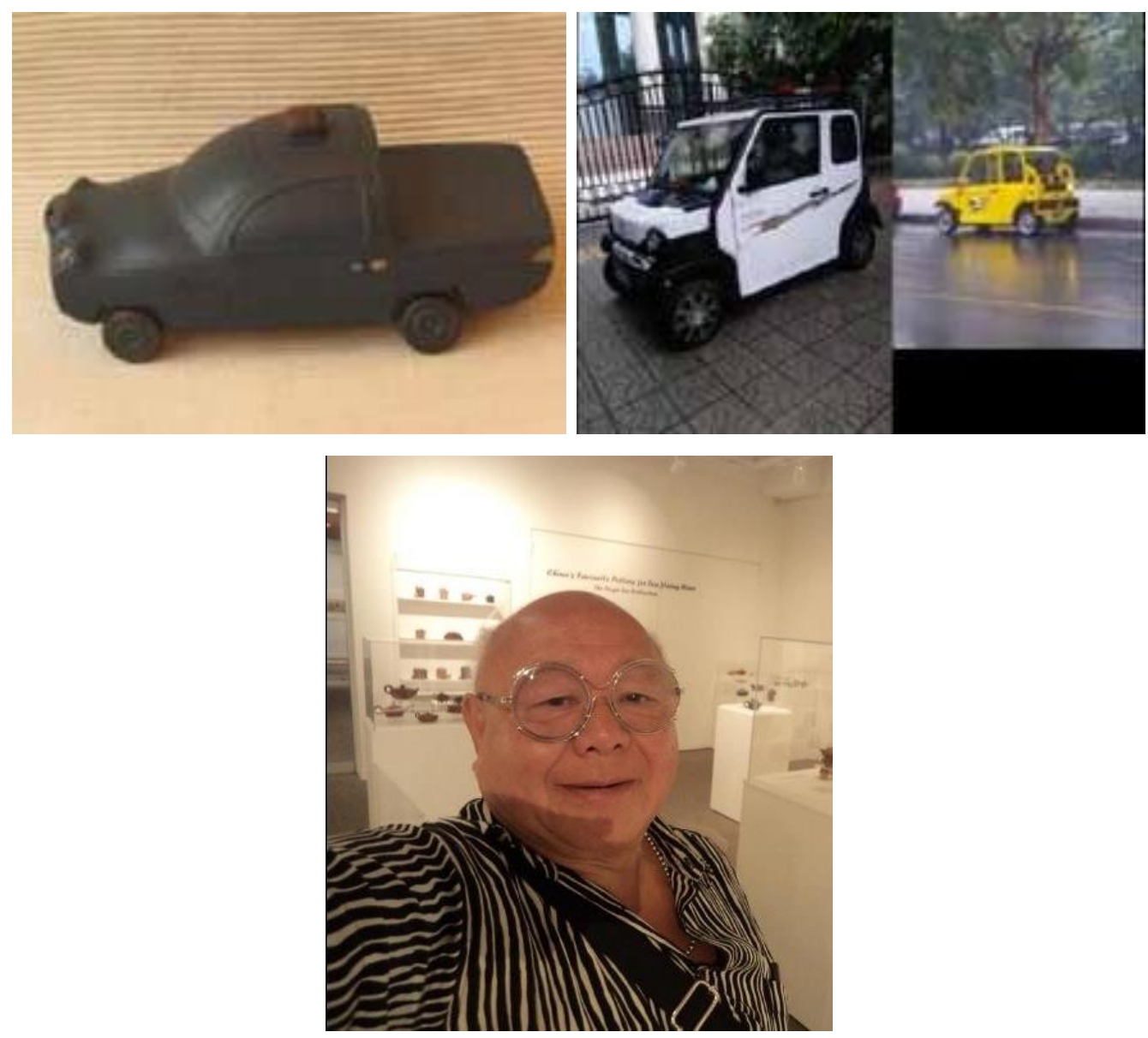

\section{References:}

- Te Oti RĀKENA, ESTABLISHING A RELEVANT CODE OF PRACTICE FOR COMMUNITY MUSIC FACILITATORS WORKING IN POSTCOLONIAL CONTEXTS, International Journal of Creativity and Innovation in Humanities and Education, Vol. 1 No. 1, 2018, pp. 24-38.

Received: July 23, 2018

Accepted: September 9, 2018 